\title{
Evaluation of the Transformation Mechanisms and Mechanical Properties of Ferrite - Martensite Microalloyed Steels
}

\author{
Ovri Henry*, Kamma Celestine Monde ${ }^{\mathrm{b}}$ \\ ${ }^{\mathrm{a}}$ Department of Welding/Fabrication Engr., Delta State Polytechnic, P.M.B 1030, \\ Ogwashi-Uku, Delta State, Nigeria \\ ${ }^{\mathrm{b}}$ Department of Materials and Metallurgical Engineering, University of Lagos - Nigeria
}

Received: October 29, 2007; Revised: March 3, 2008

\begin{abstract}
The influence of starting point microstructures on the transformation mechanisms and mechanical properties of a micro alloyed steel after annealing in the $\alpha+\gamma$ region have been investigated. Three different microstructures: austenite, pearlite in a ferrite matrix and martensite were used as starting point microstructures for the production of dual $(\alpha+\alpha)$ phase structures in the test steel. Photomicrographs obtained from metallographic examination of the heat treated samples were used as criteria for the assessment of results obtained from impact toughness and hardness testing. The results obtained showed that the transformation mechanisms and hence the morphology of ferrite - martensite microalloyed steels are strongly influenced by their initial microstructural details. Ferrite - martensite structures produced via the intercritical quench (IQ) treatment, with martensite as the starting point microstructure, have the best combination of hardness and impact energy.
\end{abstract}

Keywords: step quenching, intercritical quenching, intercritical annealing

\section{Introduction}

Over the past two decades, a group of steels with low carbon contents $(0.05-0.25 \% \mathrm{C})$ in addition to small quantities of alloying elements such as chromium, nickel, molybdenum, copper, nitrogen, vanadium, niobium, titanium, tungsten, and zirconium, used in various combinations and concentrations have been developed ${ }^{1}$. The chemical composition and processing of these steels are the usual factors that are varied to increase their mechanical properties. They contain about $1 \%$ manganese and less than $0.5 \%$ copper to produce solid solution strengthening of the ferrite and also small concentrations - less than $0.5 \%$ of other alloying elements for additional strengthening and other effects $^{2}$. These steels, referred to as Micro alloyed or High Strength Low Alloy Steels (HSLA), have made a most attractive proposition in many engineering applications such as in automobiles, pipelines for conveyance of petroleum products, bridges and other structural applications. Thus, they have to a considerable degree replaced quenched and tempered steels in many applications due to their relatively lower cost, moderate strength, good toughness, fatigue strength, and resistance to atmospheric corrosion and good weldability ${ }^{1,2,3}$. Micro alloyed steels also give improved strength to weight ratios over convectional steels. These steels have undergone further developments resulting in the production of a family of micro alloyed steels known as Dual Phase or Ferrite Martensite Microalloyed Steels ${ }^{3}$. Ferrite Martensite microalloyed steels are fast becoming one of the most popular and versatile materials in today's automotive industry, where they have replaced the more conventional HSLA steels. According to United States $\mathrm{Steel}^{4}$, they offer a great opportunity for part weight reduction. The improved formability, capacity to absorb crash energy and ability to resist fatigue failure has driven this substitution.

These steels are processed to give a microstructure of ferrite containing small uniformly distributed regions of martensite. This composite structure is of interest, because the required microstructures can be simply produced by utilizing solid-state phase transformations without resorting to mechanical or thermo mechanical treatments ${ }^{5}$.

Several workers have examined these steels to determine the effect of size and volume fraction of the hard phase (martensite) on properties. Smallman ${ }^{6}$ reports that the flow stress and tensile strength of these steels increase with a corresponding decrease in ductility with about $20 \%$ volume fraction of the martensite producing the optimum properties. However, recent work by Bag et al. ${ }^{7}$ has shown that dual phase steels containing approximately equal amounts of finely dispersed ferrite and martensite phases (50 to 60\%) exhibit the optimum combinations of high strength and ductility with impact toughness.

Dual phase steels can be obtained by adopting suitable heat-treatment procedures ${ }^{3,5,7}$. This present work examines the microstructures of dual phase (ferrite - martensite) structures of micro alloyed steel produced via three different routes, namely: Intercritical Annealing (IA); Step Quenching (SQ) and Intercritical Quenching (IQ)

The aim is to determine the effect of the starting point microstructures and holding time on the:

- Transformation mechanisms of micro alloyed steels.

- Hardness and impact energy of the final products and subsequently to determine optimum conditions for the production of dual phase micro alloyed steels.

\section{Experimental Procedure}

\subsection{Materials/methods}

The micro alloyed steel used for this investigation was in the form of a pipe $60 \mathrm{~mm}$ diameter $\times 9 \mathrm{~mm}$ thick. The chemical analysis of the steel was done with the aid of an ARL340 metal analyzer. Details of the results are given in Table 1.

The steel pipe was machined into standard shapes for impact and hardness testing after which the following heat-treatment schedules were carried out:

All the samples were first normalized to ensure uniform prethermal history for all the samples. This involved heating to $920{ }^{\circ} \mathrm{C}$ followed by cooling in air. The samples were then subjected to three different types of heat treatment. These are: 
Table1. Chemical composition of the steel specimen.

\begin{tabular}{lccccccccccccccc}
\hline Element & $\mathrm{C}$ & $\mathrm{Si}$ & $\mathrm{S}$ & $\mathrm{P}$ & $\mathrm{Mn}$ & $\mathrm{Cr}$ & $\mathrm{Mo}$ & $\mathrm{Cu}$ & $\mathrm{As}$ & $\mathrm{Sn}$ & $\mathrm{Al}$ & $\mathrm{Pb}$ & $\mathrm{Ca}$ & $\mathrm{Zn}$ & $\mathrm{Fe}$ \\
\hline$\% \mathrm{wt}$ & 0.1404 & 0.1926 & 0.0103 & 0.0076 & 0.7758 & 0.0873 & 0.0250 & 0.2015 & 0.0078 & 0.0085 & 0.0076 & 0.0002 & 0.0007 & 0.0059 & 98.418 \\
\hline
\end{tabular}

a) Intercritical annealing (IA), which entailed annealing at $790^{\circ} \mathrm{C}$ for $30,45,60,75$, 90 minutes respectively, followed by quenching in water;

b) Intermediate quenching (IQ), which entailed holding at $920^{\circ} \mathrm{C}$ for 30 minutes followed by quenching in water, reheating to $790{ }^{\circ} \mathrm{C}$ and holding for $30,45,60,75$ and 90 minutes respectively before quenching in water again; and

c) Step quenching (SQ), which entailed holding at $920{ }^{\circ} \mathrm{C}$ for 30 minutes, furnace cooling to $790{ }^{\circ} \mathrm{C}$ and holding for 30,45 , 60,75 and 90 minutes followed by quenching in water.

After the heat treatment, impact test was carried out on the samples by means of a Pendulum Charpy Impact Tester, while hardness of the samples was determined using a Rockwell hardness directreading indentation machine with scale $\mathrm{C}$. Small samples cut from the heat-treated samples were metallographically examined with an optical microscope at a magnification of $\times 150$.

\section{Results}

\subsection{Rockwell hardness and charpy impact tests}

Figure 1 shows the variation of hardness obtained with holding time, while Figure 2 is the plot of charpy impact energy against holding time.

\subsection{Microscopic investigation}

The photomicrographs of the as-received steel and that of the normalized steel are shown in Figure 3 and 4 respectively. The photomicrographs of the intercritically annealed samples are shown in Figures 5-8, those of the step-quenched in Figures 9-13, while those of the intermediate quench are shown in Figures 14-18.

\section{Discussion of Results}

\subsection{Intercritical annealing}

The starting point microstructure used for this treatment, intercritical annealing, was fine pearlite in a ferrite matrix (Figure 3). Examination of the photomicrographs (Figures 5 to 8) obtained after this treatment, reveal that they consist essentially of martensite laths in a ferrite matrix. The ferrites are of irregular shapes mixed with martensites, which lie mostly along prior austenite grain boundaries. Precipitation of carbide particles is also evident as the holding time is increased. Figure 1 shows the variation of hardness (HRc) of the intercritically annealed samples with holding time. A sharp increase in hardness with holding time is initially observed. This is however followed by a steady drop after holding for 60 minutes.

The increase in hardness can be attributed to increase in the volume fraction of martensite with holding time. This invariably leads to strengthening of the matrix. Cota et al. ${ }^{8}$ also carried out similar treatments on a microalloyed steel and obtained hardness values that compare reasonably with those obtained in this work. The decrease in hardness after holding for 60 minutes can be attributed to the coarsening of the carbide particles with increase in holding time (Figures 5-6). This has a softening effect on the microstructure so formed. The decrease in hardness therefore implies that the softening effect of the coarse carbide particles takes pre eminence over

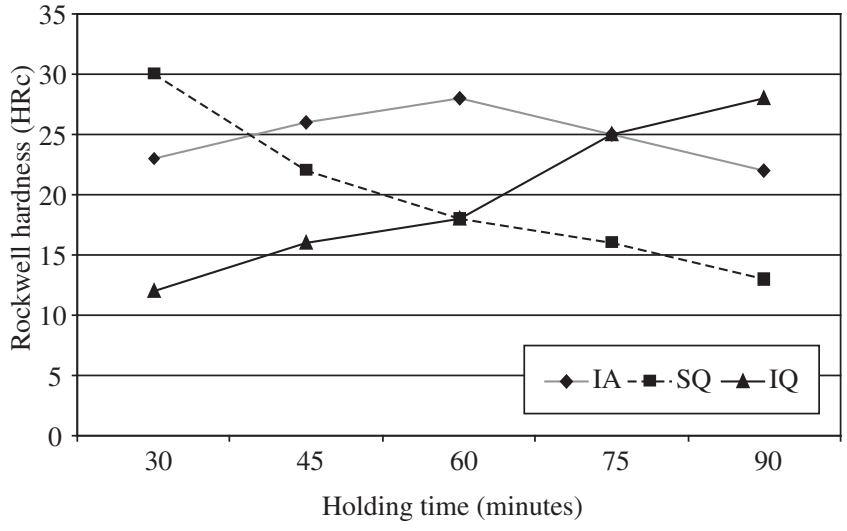

Figure 1. Rockwell hardness vs. holding time.

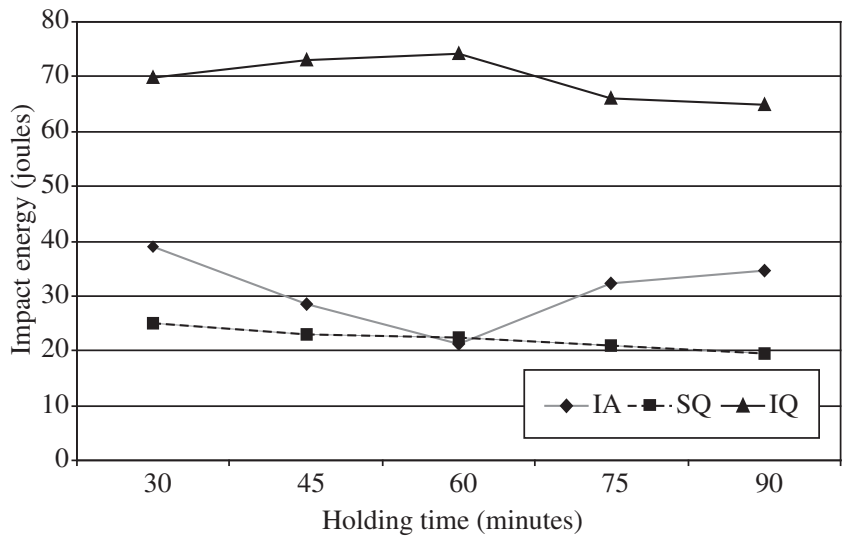

Figure 2. Charpy impact energy vs. holding time.

the matrix strengthening effect of the martensite, after holding for 60 minutes.

Figure 2 shows the variation of Charpy impact energy with holding time for the different types of heat treatment. The impact energy of the samples given this treatment had the highest value of $39 \mathrm{~J}$ after holding for 30 minutes. A sharp drop in this impact energy value was however observed as the holding time was increased up to 60 minutes. This was thereafter followed by a remarkable improvement in the impact energy up to 90 minutes.

Dhua SK et al. ${ }^{9}$ in their work attributed decrease in impact energy to both the negative effect of matrix strengthening and impurity segregation at the grain boundaries. Matrix strengthening occurred as a result of the increasing volume fraction of martensite and also as result of the precipitation of carbide particles at prior austenite grain boundaries. The improvement in impact energy of the samples after 60 minutes can be attributed to the coarsening of the carbide particles that became pronounced during this period of holding. Dhua SK et al. ${ }^{9}$ also attributed the phenomenal improvement in impact toughness to the over aged microstructure of partially recovered matrix and coarse precipitates. They suggest that these might have helped in arresting the propagation of cleavage cracks. 


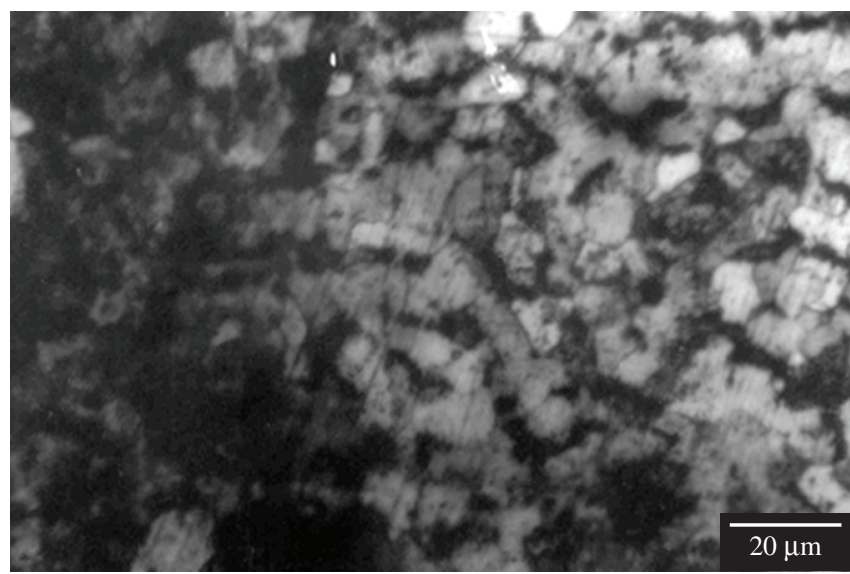

Figure 3. As- received microstructure consisting of coarse pearlite

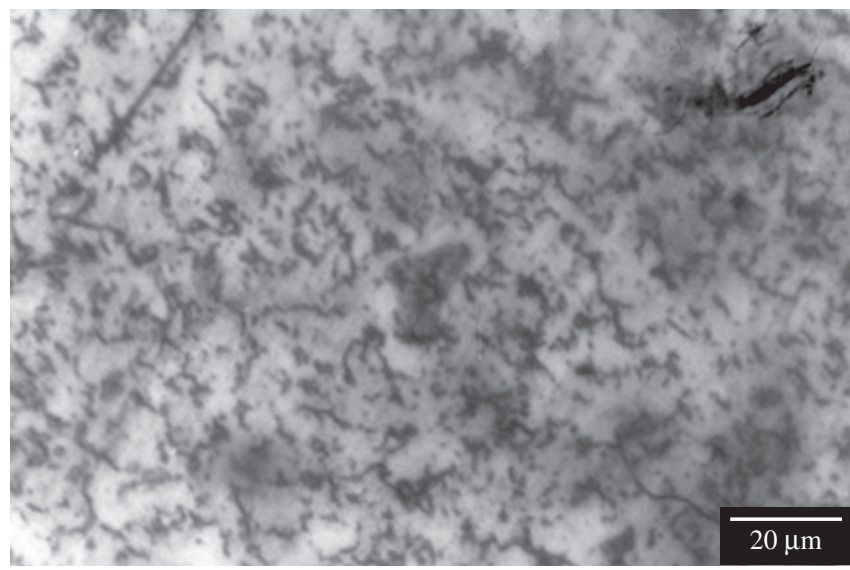

Figure 4. Normalized microstructure consisting of fine pearlite.

\subsection{Step quenching}

Figures 9 to 13 are the photomicrographs of the samples that were given the "Step Quench" treatment. The starting point microstructure was austenite. The rather slow cooling of austenite from $920{ }^{\circ} \mathrm{C}$ to $790{ }^{\circ} \mathrm{C}$, which took 11 minutes, resulted in the formation of proeutectoid ferrite (gray areas) and austenite, which transformed to large martensite laths (dark areas) on quenching from the intercritical temperature region (see Figures 9 and 10). Smallman ${ }^{6}$ stated that the morphology of this ferrite depends on the usual precipitation variables such as temperature, time, carbon content and grain size, and growth occurs preferentially at grain boundaries and on certain crystallization plates. Precipitation of carbide particles is also noticed along the grain boundaries as the holding time is increased (see Figures 10 and 11). These carbide particles pin down the ferrite grains at locations where they are precipitated and therefore hinder the rather regular growth of the ferrite along the grain boundaries. The result of this as seen in Figures 11-13, is that the ferrite grains are of irregular shapes mixed with equally irregularly curved globular martensite constituting a continuous network along prior austenite grain boundaries. These features became more pronounced with increase in temperature.

From Figure 1, variation of Rockwell hardness (HRc) with the different treatments, it can be seen that in the case of step quench treatment there is a steady drop in the hardness value from $30 \mathrm{HRc}$ to $13 \mathrm{HRc}$, as the holding time increased. This can be attributed to the decreasing volume fraction of martensite as the holding time increased.
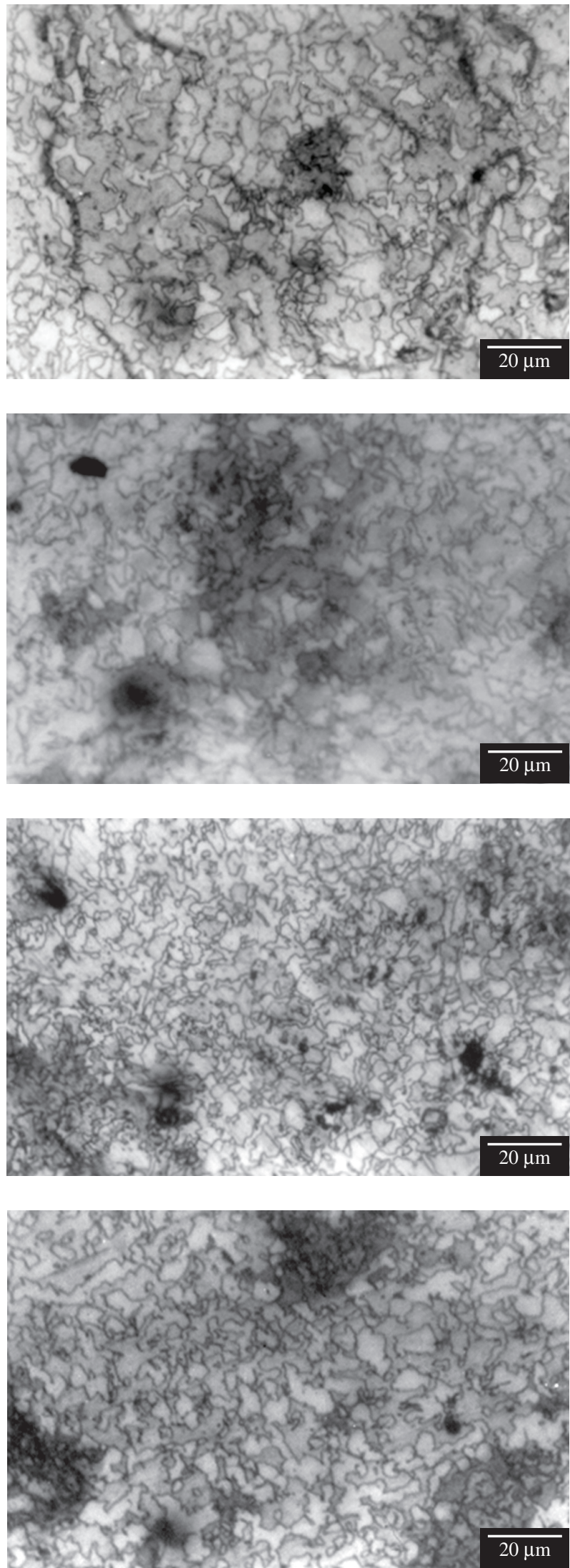

Figures 5-8. Photomicrographs of IA45, IA60, IA75 and IA90 respectively. These samples were intercritically annealed. They consist essentially of martensite laths in a ferrite matrix. The ferrites are of irregular shapes mixed with martensites which lie mostly along prior austenite boundaries. 

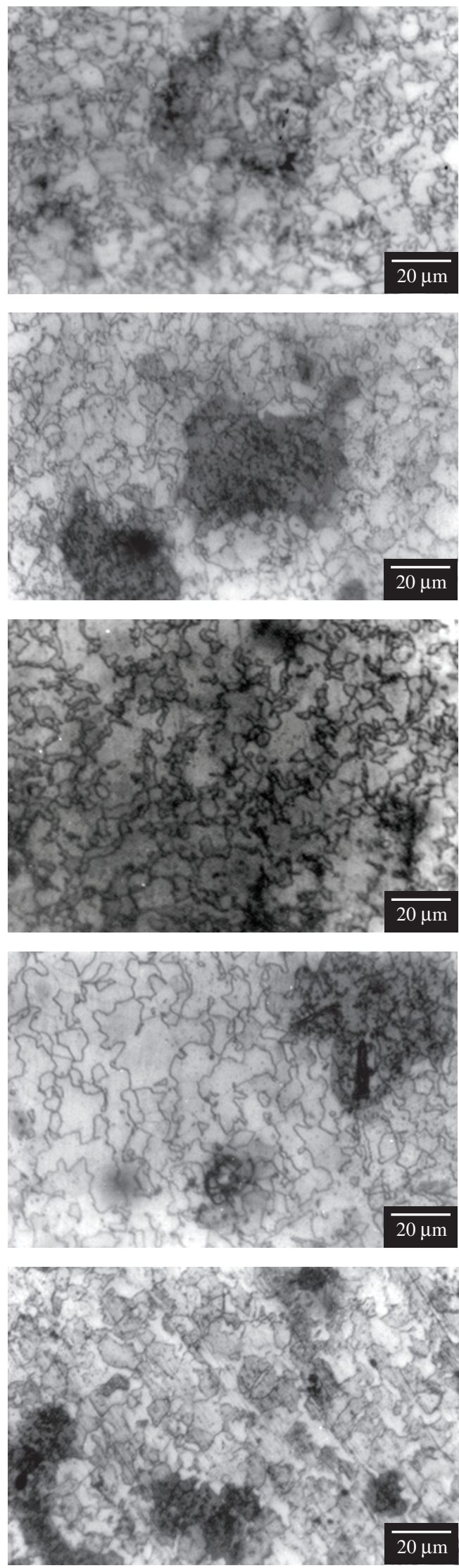

Figures 9-13. Photomicrographs of SQ30, SQ45, SQ60, SQ75, and SQ90 respectively. Step quenching from the intercritical region after holding for different times produced microstructures consisting of irregularly curved globular martensite constituting a continuous network in a ferrite matrix.
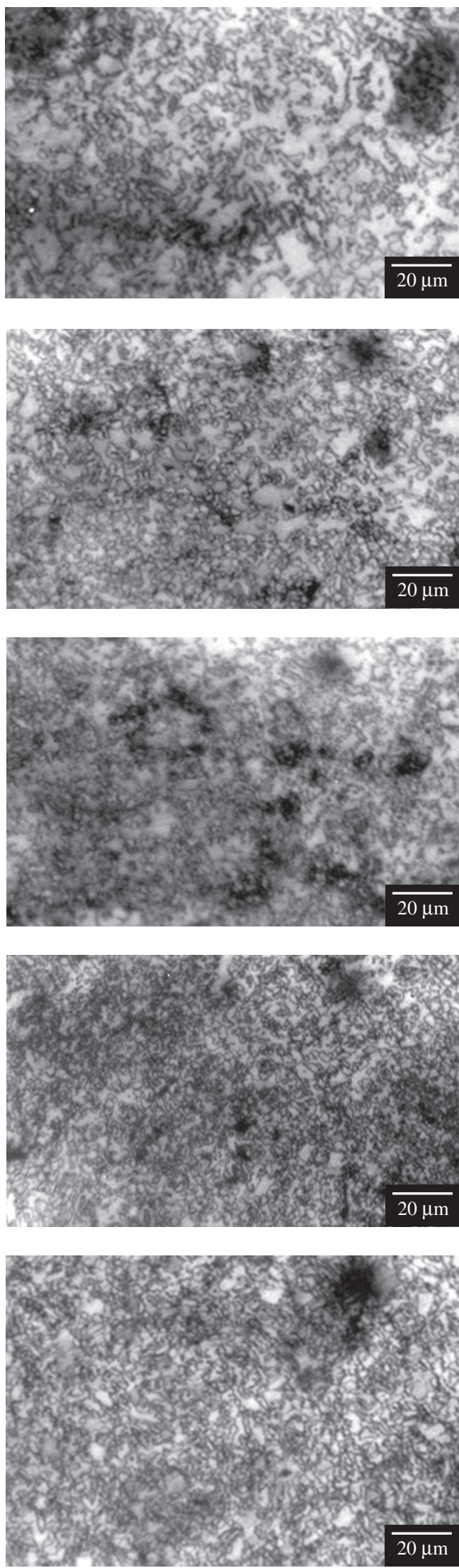

Figures 14-18. Photomicrographs of IQ30, IQ45, IQ60, IQ75, and IQ90 respectively. These samples were intercritically quenched. They consist essentially of tiny globular martensite particles, with some precipitates of carbide formed along prior austenite boundaries, in a ferrite matrix. 
From Figure 2, it is seen that the impact energy of the step quenched samples also decreased, gradually with time. This behaviour is remarkable because it is a departure from the usual phenomenon, where impact energy is found to increase as the volume of fraction of martensite is decreased ${ }^{7,9}$. Yang and $\mathrm{Chen}^{5}$ reported that the impact properties of dual ferrite - martensite, (DFM), steels are strongly affected by three major structural factors: morphology (shape, size and distribution) of the DFM structure, volume fraction of martensite particles and toughness (carbon content) of the martensite particles. They stated further that as the volume fraction of martensite decreases it is expected that the carbon content in the martensite will increase, therefore toughness and hence impact properties of martensite will deteriorate. Another reason for this behaviour may be the effect of matrix strengthening, which according to Dhua SK et al. ${ }^{9}$ leads to a decrease in impact energy. The precipitation of carbide particles, which invariably leads to matrix strengthening, was prominent in this treatment as the holding time was increased.

\subsection{Intercritical quenching}

Figures 14-18 are the photomicrographs of samples given the intercritical quench treatment.

The initial microstructure used for this treatment was martensite formed as a result of quenching from the austenitizing temperature $\left(920^{\circ} \mathrm{C}\right)$. The martensite so formed undergoes gradual transformation to ferrite and austenite on annealing at the intercritical temperature $790{ }^{\circ} \mathrm{C}$. The formation of austenite from the martensite structure has been found to occur by classical heterogeneous nucleations at such lattice imperfections as prior austensite grain boundaries, martensite lath boundaries, matrix /carbide interface and spheroids in ferrite ${ }^{5,7}$. Examination of the photomicrographs reveals that after holding for 30 minutes, the microstructure consist of tiny but numerous globular martensite, with some precipitates of carbide formed along prior austenite boundary, in a ferrite matrix (see Figure 14). The volume fraction of martensite is observed to increase with holding time. It was also observed that there was little or no increase in the size of the martensite globules with increase in holding time. This must have been due to the fact that the carbide particles precipitated in prior austenite grain boundaries pinned down the grain boundaries.

Figure 1 reveals that there is a steady rise in the hardness (12HRc to $28 \mathrm{HRc}$ ); of the intercritically quenched samples as the holding time increases. This increase in hardness is as a result of the enrichment of the microstructure with austenite (that is, increase in volume fraction of martensite) as the holding time increased.

Figure 2 shows the variation of impact energy with holding time for the different treatments. It can be seen that in the case of intercritical quench treatment (IQ), there was an initial rise in the impact energy but this was followed by a sharp drop after holding for 60 minutes. This is also a departure from the usual phenomenon where increase in volume fraction of martensite is known to cause a decrease in impact energy. As earlier discussed, the impact properties of dual ferrite -martensite steels have been found to be strongly affected by three major structural factors: morphology (shape, size and distribution) of the ferrite - martensite structure, volume fraction of martensite, $\mathrm{V}_{\mathrm{m}}$, and toughness (carbon content) of the martensite 5 . Bag et $\mathrm{al}^{7}$ also reported that the impact energy of these steels with finely dispersed constituents of ferrite and martensite are more superior to those with a coarse or banded structure and they exhibit a peak for a volume fraction of 0.5 to 0.6 . The initial increase in impact energy with holding time may therefore be as a result of the finely dispersed martensite globules in the ferrite matrix. The influence of this morphology must have taken pre eminence over the negative effect of matrix strengthening on impact properties, within the first 60 minutes of holding. However, the effect of matrix strengthening caused by a high volume fraction of martensite (most probably greater than $0.6 \mathrm{~V}_{\mathrm{m}}$ ), and carbide precipitation; which are more pronounced after holding for 60 minutes must have suppressed the positive effect of the morphology described above. Hence the decrease in impact energy observed after holding for 60 minutes.

\section{Conclusions}

On the basis of the morphologies of the resulting microstructures, and the mechanical tests (hardness and Charpy impact tests) carried out, the following conclusions were made:

1) The morphology and consequently the mechanical properties (hardness and impact toughness) of ferrite - martensite microalloyed steels are strongly influenced by their initial microstructural details;

2) Ferrite - martensite structures produced via Intercritical Quenching treatment, with a starting point microstructure consisting of martensite, have the best combination of hardness and impact properties; and

3) The initial martensite structure encourages the formation of fine globules of martensite in the ferrite matrix. The fine globular structures of martensite obtained from the intercritical quench treatment are a consequence of the heterogeneous nucleation sites provided by the martensite phase for austenite nucleation during the two phase annealing stage.

\section{References}

1. Honeycombe RWK, Bhadeshia HKD. Steels, microstructure and properties. $2^{\text {nd }}$ ed. London: Edward Arnold; 1995.

2. Budinski KG. Engineering materials: properties and selection. $2^{\text {nd }}$ ed. Virginia: Reston Publishing Co; 1993.

3. Ballinger NK, Naylor DJ, Dasarathy R, Hudd R, Hessy J. Developments in dual phase steels by the British steel corporation. In: Proceedings of International Conference of the Metals Society; 1981, Warrendale: The Minerals, Metals \& Materials Society; 1981. p. 272-281.

4. United States Steel. Pittsburgh: US Steel. [home page on the internet]. c2005-2008 [cited 2007 March 24]; Available from: http//: http://www. uss.com/corp/products/msds /3H012.pdf.

5. Yang JR, Chen LJ. Dual ferrite - martensite treatments of a high - strength low alloy steel, J of Matls Sci. 1991; 26: 889-898.

6. Smallman RE. Modern physical metallurgy. $9^{\text {th }}$ ed. Oxford: Butterworth Heinemann Ltd; 1995.

7. Bag A, Ray KK, Dwarakadasa ES. Influence of martensite content and morphology on tensile and impact properties of high - martensite dual phase steels. Met \& Mat Trans. 1991; 39A: 1193-1202.

8. Andre BC, Fernando LGO, Anderson LRB, Cassio AML, Fernando GSA. Microstructure and mechanical properties of a microalloyed steel after thermal treatments. Matls Res. [serial on the Internet]. 2003 [cited 2007 August 18]; [5 screens]. Available from: http://www.scielo.br/scielo.php?script=sci_arttext\&pid= S1516-14392003000200002$\& \operatorname{lng}=$ en $\&$ nrm $=$ iso

9. Dhua SK, Mukerjee D, Sarma DS. Influence of tempering on the microstructure and mechanical properties of HSLA - 100 steel plates. Met \& Mat Trans. 2001; 32A: 2259-2270. 
